\title{
Non-Metastatic Leiomyosarcoma
}

National Cancer Institute

\section{Source}

National Cancer Institute. Non-Metastatic Leiomyosarcoma. NCI Thesaurus. Code C8814.

Leiomyosarcoma that is confined to the site in which it initially manifested. 